\title{
Customization of an optical probe device and validation of a signal processing procedure to study gas-liquid-solid flows. Application to a three-phase internal-loop gas-lift Bioreactor
}

\author{
André Mota ${ }^{a}$, António Ferreira ${ }^{a}$, António A. Vicente ${ }^{\mathrm{a}}$, Philippe Sechet ${ }^{\mathrm{c}, *}$, \\ Jean M.F. Martins ${ }^{\mathrm{b}}$, José A. Teixeira ${ }^{\mathrm{a}}$, Alain Cartellier ${ }^{\mathrm{c}}$ \\ a IBB, Institute for Biotechnology and Bioengineering, Centre of Biological Engineering, University of Minho, Campus Gualtar, 4710-057 Braga, Portugal \\ ${ }^{\mathrm{b}}$ LTHE, Laboratoire d'Etude des Transferts en Hydrologie et Environment, UJF-CNRS-INPG, BP 53, Domaine Universitaire, 38041 Grenoble cedex 9, France \\ ' LEGI, Laboratoire des Ecoulements Géophysiques et Industriels, UMR 5519, UJF-CNRS-INPG, BP 53, Domaine Universitaire, 38041 Grenoble cedex 9, France
}

\section{H I G H L I G H T S}

- Customization of optical device for application in three-phase systems.

- Application and validation of new technique at lower solids content.

- Solids decrease gas hold-up in riser and increase system complexity.

- Validation of results using additional techniques.

\section{A R T I C L E I N F O}

\section{Article history:}

Received 6 October 2014

Received in revised form

5 August 2015

Accepted 26 August 2015

Available online 11 September 2015

\section{Keywords:}

Multiphase reactors

Bioreactors

Hydrodynamics

Solids

Optical probe

\begin{abstract}
A B S T R A C T
The study of local hydrodynamic properties of three-phase bioreactors in biotechnology processes is of great importance, mainly because of the complex interaction between bioreactor and microorganisms. However, classical techniques used for measuring local hydrodynamic properties such as single needle probes are mainly limited to two-phase flows. In this work it was developed and validated a new system, based on the customization of an optical probe initially designed in LEGI. The necessity of a new system was due to the agglomeration of the solid-phase (spent grains which are used as the micro-organisms carrier for the targeted application) around the optical tip, which influences the measurements. This new system allows for the measurement of the main local gas-phase properties in a complex gas-liquid-solid mixture. The new system was first validated for air-water system in an internal loop gas-lift reactor and then applied to a spent grains-air-water mixture at low solid load in an internal gas lift reactor. In addition, experiments using complementary techniques (as high speed camera and PIV) were performed that allowed for the validation of the new system and the explanation of possible physical mechanisms that are underlying on this multiphase system. The system developed has the potential for improvement and use in several biotechnology applications.
\end{abstract}

(c) 2015 Published by Elsevier Ltd.

\section{Introduction}

The study of gas-lift reactors hydrodynamics has been increasing over the last decades, especially due to the several biotechnological applications of these reactors. These applications

\footnotetext{
Abbreviations: AST, Automatic statistic tool; $\mathrm{B}_{\mathrm{CD}}$, Bubble complexity degree; HSC High speed camera; iGLR, Internal-loop gas-lift reactor; MIA, Manual measurements; OP, Optical probe; PIT, Particle image tracking; PIV, Particle image velocimetry; TGV, Treatment for gaseous velocity; WAI, Water absorption index

* Corresponding author.

E-mail address: philippe.sechet@legi.grenoble-inp.fr (P. Sechet).
}

are called $(g-l-s)$ systems as they are composed by three phases: gas $(g)$, liquid $(l)$ and solid $(s)$. In some cases the inert solid phase can act as the carrier for immobilization of living biomass.

More specifically, in the long term, we are interested in continuous high cell density fermentation systems using immobilized cell technology: the lack of knowledge about these bioreactor hydrodynamics hampered their industrial development.

To better understand the local hydrodynamics of such a complex system, in particular the effect of the solid and biomass on the gas-liquid $(g-l)$ mixture, the characterization of each phase requires the use of different and refined measurement techniques. The techniques for studying the local gas-phase properties can be 
divided into two categories: non-invasive and invasive. Among non-invasive techniques we can list: particle image velocimetry (PIV), particle image tracking (PIT) and visualization techniques. On the other hand, invasive techniques for studying local gasphase properties use mainly phase detection probes (Boyer et al., 2002; Cartellier, 1992). Most of the invasive techniques, such as phase detection probes, are cheaper and easier to apply in industrial processes than non-invasive ones. The reasons for this are: (1) the typical turbulent flow regimes found in industrial reactors; (2) opaque reactors and (3) the ability to continuously collect data online (Boyer et al., 2002). Sensors are based on temperature, capacitance, optical and conductivity properties of the system. Frequently, they are applied on two-phase flow(Jhawar and Prakash, 2007; Olivieri et al., 2007) and more recently to three-phase flow systems (Mena et al., 2008; Hooshyar et al., 2010; Wu et al., 2008), usually at low solids holdup (Boyer et al., 2002).

The present work focuses on the customization of an optical probe device to study gas-liquid-solid system. It is indeed a prerequisite before studying the complete bioreactor behaviour with biomass. More specifically, given the industrial applications targeted, the solid considered in this paper is spent grain whose properties are different from the solids used in previous work (Mena et al., 2008). Therefore specific developments were required. The experiment was performed in an internal loop gas lift reactor (iGLR) which also corresponds to the targeted industrial applications.

In the present manuscript, several measurements techniques were used. The liquid and solid phase hydrodynamic behaviour was characterized using PIV and a visualization technique respectively. In the frame of the gas phase characterization, two techniques were used: photographic method (high speed camera denoted HSC in this paper) and optical probe (denoted OP). This choice was driven by the need for complementary measurement methods to assure the correctness of the optical probe data.

The main limitations of HSC are the inability to use it at high gas flows and at high solid loads. The reactor wall transparency, out of focus, illumination and image analysis are among other known limitations (Ferreira et al., 2012). The reactor wall, focus and illumination can be solved/reduced experimentally (Mena et al., 2008, 2005b). Concerning image processing, automatic image analysis is not an easy task mainly because of the identification of single and overlapping bubbles. Usually this is done by manual or semi-manual methods (Ferreira et al., 2012). Recently an automatic method has been developed, which allows the identification between a single and a group $(\geq 2)$ of bubbles, however this is also limited under experimental conditions cited above. The classification is based on a series of probabilities and it also allows the characterization of the system's complexity (Ferreira et al., 2012). When bubbles are classified, the commercial programs available are then able to determine bubble properties such as: the projected area, equivalent diameter, the Feret diameters distribution, elongation and sphericity (Ferreira et al., 2012).

Among other measurement tools, over the last two decades optical probes have been developed and successfully applied in bubble column reactors (Cartellier, 1998; Hamad and He, 2010; Hong et al., 2004; Shen et al., 2008). Their operation is relatively simple: it is based on the change of the refractive index of the medium in which the sensitive tip is located. Depending on this refractive index, more or less light intensity is sent back to a detector: this allows the measurement of the phase indicator function. From this indicator function, it is possible to measure gas-phase concentrations (holdup). Under some conditions, it is also possible to measure bubble velocity and then, bubble size distributions, mean interfacial area and mean Sauter diameter. To measure parameters such as bubble velocities, diameter and interfacial area double (or multi) tip probes are often used (Boyer et al., 2002; Chaumat et al., 2005), however their major drawback is the low spatial resolution. Cartellier (1990) developed a single tip probe which allows an accurate description of the flow. This type of probes was used in our work and is able to measure void fraction and bubble velocity (Cartellier, 1990). Moreover, due to their small size the spatial resolution is very high. The optical probe principle as well as a complete description of the LEGI optical probes signal processing methods (treatment for gaseous velocity - TGV) and main measurement errors can be found in the literature (Cartellier, 1998, 1992; Mena et al., 2008). Let us just stress that the probe manufacturing allows to control the diameter and shape of the sensitive tip (which is an almost perfect cone). That explains their high spatial resolution (smaller bubble detected, better interface piercing). Because of this controlled conical shape, Cartellier (1990) showed that the interface piercing time could be related to the bubble velocity through a calibration curve. However, that does not completely supress some uncertainties on the data. Using one of the probes manufactured in LEGI, Vejrazka et al. (2010) found that gas holdup measurement errors obtained when this OP is used are still due to the intrusive character of these probes. They studied the interaction between an optical probe and a bubble: where Optical probe displacement and bubble deformation (leading to imperfect tip de-wetting, bubble deceleration or deflection) were found to be the causes for the measurement errors displayed, especially when chords distribution is calculated (Vejražka et al., 2010). However it is believed that the ability to evaluate gas holdup is not so roughly affected.

Initially the long term objective of this work was to study the local influence of spent grains carrying immobilized cells through the hydrodynamic properties of the three-phase iGLR. The cause of this interest is the recent developments on continuous high cell density fermentation systems using immobilized cell technology and the lack of knowledge associated with the bioreactor hydrodynamic aspects.

During the course of this work some difficulties related with measurement techniques arose, especially the use of OP in a threephase g-l-s system whenever spent grains are used. Therefore the first step was to study the local hydrodynamics of a three-phase iGLR using spent grains as solid-phase. This included the development and calibration of a new method to measure gas-phase properties using an OP in a system where spent grains were present as well as the evaluation of the effect of low solid concentration in iGLR local hydrodynamics at low gas flow rates $\left(U_{G r} \leq 1 \mathrm{~cm} / \mathrm{s}\right)$. This is the subject of the present paper.

\section{Material and methods}

\subsection{Experimental set up}

\subsubsection{Experimental apparatus}

The iGLR used in this work is of the concentric draught tube type with an enlarged top section for degassing and a total working volume of $6 \mathrm{~L}$ (Fig. 1). The angle between the conical sector and the main body was $51^{\circ}$. Gas was injected through a distributor (1-cm diameter) with five needles, each of $0.2 \mathrm{~mm}$ in diameter and placed $1.7 \mathrm{~cm}$ below the annulus of the riser. The water level in the reactor was kept constant. Temperature and pressure were ambient $\left(21^{\circ} \mathrm{C}\right.$ and $\left.1 \mathrm{~atm}\right)$. The desired gas flow was adjusted with a rotameter (MR3000 series Flowmeter, Key Inst., Trevose, USA) operating at $1 \mathrm{~atm}$ and $21^{\circ} \mathrm{C}$.

\subsubsection{Solids properties}

The particles tested on this work were spent grains, a cellulosebased solid. These solids are generally hydrophobic and have a negative charge at low $\mathrm{pH}$, which along with their rugosity and 


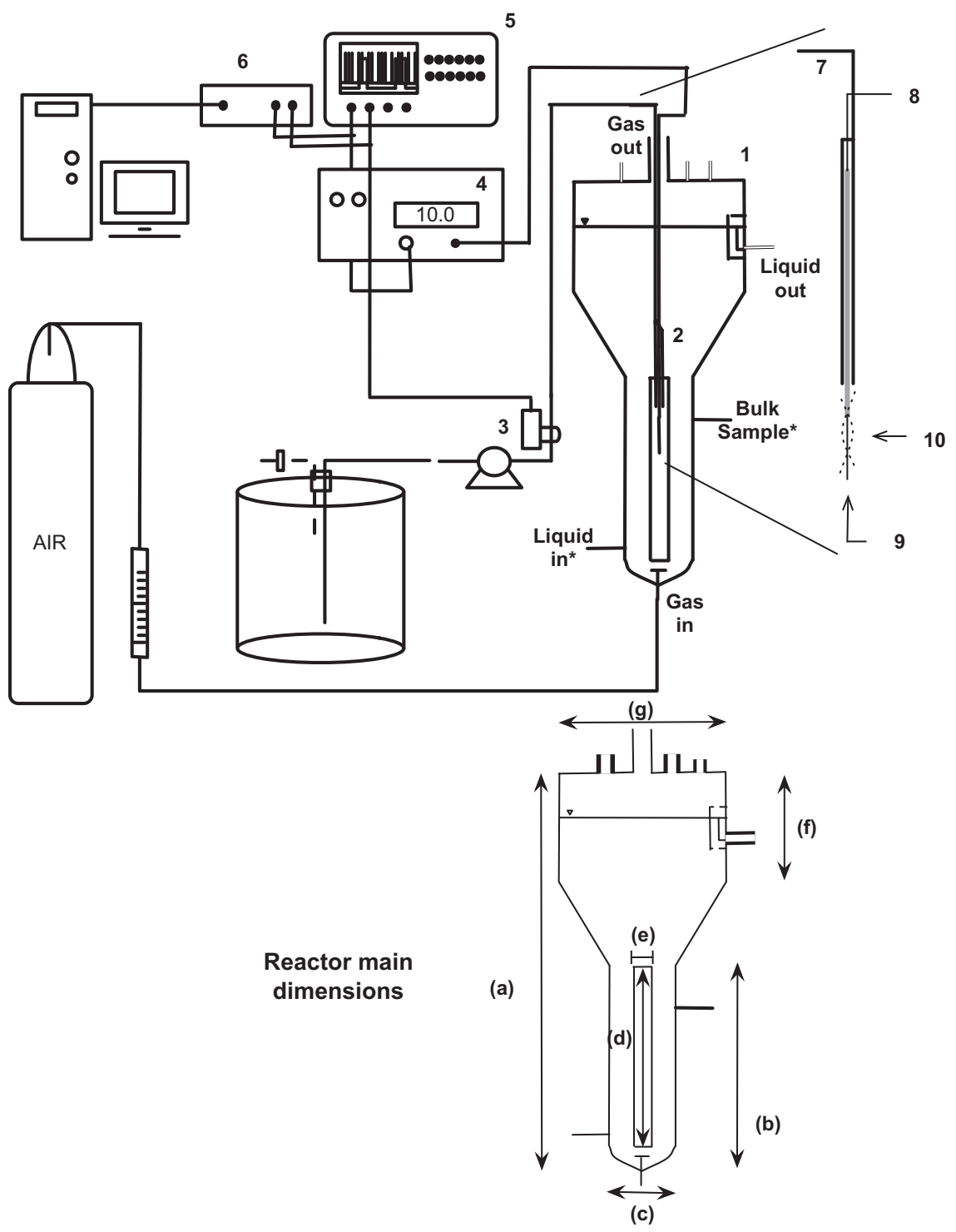

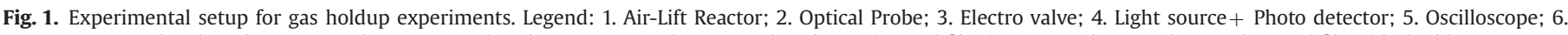

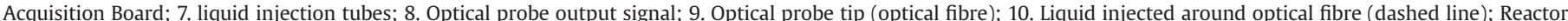

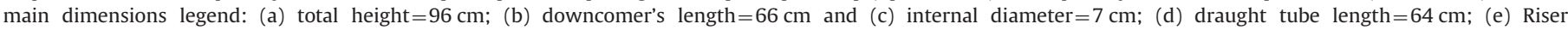
diameter $=3 \mathrm{~cm}$; (f) Top cylindrical part's length $=19.5 \mathrm{~cm}$ and $(\mathrm{g})$ diameter $=19 \mathrm{~cm}$. (These inlet and outlet were not used during the measurements).

non-uniform surface full of cavities and holes allows them to immobilize cells very effectively. Spent grains were pre-treated according to the acid/base method proposed by Brányik et al. (2001). Spent grains after pre-treatment are almost flat particles, with equivalent diameter $d_{e q}<5 \mathrm{~mm}$ and density $\rho=1037 \mathrm{~kg}$ WET BAsIs $/ \mathrm{m}^{3}$. The size distribution of the particles was determined by sieving into fractions using a portable sieve shaker (Model Analysette, Fritsch, Germany). With the obtained data, the equivalent diameter was evaluated. The solids are completely wettable with a water adsorption index (WAI) of $8.12 \mathrm{~g}_{\mathrm{WET}} / \mathrm{g}_{\mathrm{DRY}}$ determined accordingly by Mussatto et al. (2009) and the sedimentation velocity is about $0.83 \pm 0.16 \mathrm{~cm} / \mathrm{s}$.

\subsubsection{Experimental conditions}

The gas flows tested were $250 \mathrm{~mL} / \mathrm{min}(0.59 \mathrm{~cm} / \mathrm{s})$ and $400 \mathrm{~mL} / \mathrm{min}$ $(0.94 \mathrm{~cm} / \mathrm{s})$, which are similar to the gas flows used in previous fermentations (Mota et al., 2011). In terms of solid concentration, the following four solid loadings were used: $0 \%, 2 \%, 4 \%, 6 \%$ (wt WET BASIS $_{\text {W }}$ vol). These are also similar to the ones used in continuous systems using immobilized cells in spent grains (Lehnert et al., 2008; Mota et al., 2011).

\subsection{Instrumentation}

\subsubsection{Optical probe}

As previously said, an optical probe was used to perform local gas properties measurement (gas holdup, bubble size and velocity) in the iGLR riser. This probe was specifically designed from the modification of a probe manufactured in LEGI. Those modifications include an injection system (Fig. 1. See caption for the dimensions) which allows a periodic cleaning of the probe tip, and authorizes the use of the probe in three phase configurations. The probe, the injection system and the specific signal processing developed in this work are presented in detail in Sections 3.1 and 3.2. The optical probe was located at $30 \mathrm{~cm}$ from the top of the riser. Measurements were performed varying the radial position: $r=0$, $\pm 7 \mathrm{~mm}$, where $r=0$ corresponds to the column axis. The few positions studied in the radial positions were imposed by the lower spatial resolution due to the injection system size. 


\subsubsection{High speed camera measurements}

To analyse the specific behaviour and influence of the spent grains in a $g-l$ mixture we used a HSC recording at 1000 frames per second. This allows for visual evaluation and confirmation of the information obtained by the optical probe using the system and method presented in Sections 2.1.1 and 2.1.3. However this was only achieved at low solid concentration (up to $2 \%$ (wt WET $_{\text {WET }}$ BASIs/vol)) because at higher values no information from images was possible to be obtained. HSC videos were recorded using the FlowView $^{\mathrm{TM}}$ program and the bubble properties (mean chord, minimum and maximum Feret diameters) analysis was performed manually. Image sizes obtained have a $1280 \times 1024$ resolution and the manual measurement error was below 5\%. Bubble velocity was determined by manually tracking bubbles between 20 frames that correspond to a time interval of 20 milliseconds. Bubble chord was determined by considering a virtual optical probe piercing a bubble in a perpendicular position. Along PIV measurements for the liquid velocity characterization in the downcomer (see below), HSC was also used to manually estimate the solid velocity in the downcomer.

\subsubsection{Statistical relevance of OP and HSC measurements}

The statistical analysis of the gas-phase properties (holdup, velocity, chord size) was carried out using single-factor analysis of variance (ANOVA), while multiple comparison tests were used to determine the statistical significance with a $95 \%$ confidence level. MATLAB software was used for the data analysis.

\subsubsection{PIV Measurements}

PIV measurements were made to determine the liquid velocity field in the downcomer. PIV is a technique that has been successfully used to determine velocity fields in single-phase flow or at low gas holdup values in a two-phase flow. The main problem with using PIV is to identify the seeding particles between the frames. Usually to discriminate well the different phases, fluorescent seeding particles are used on the liquid and the filtered signal is analysed (Boyer et al., 2002; Unadkat et al., 2009). In the current experiment, the fluid velocity measurements were performed in the downcomer. For technical constraints the velocity field was only measured in the outer part of the downcomer and other parameters (such as the liquid flowrate or mean velocity) were computed from assumption on the complete profile shape. The PIV-LIF system (Particles Image Velocimetry by Laser Induced Fluorescence) used in these present experiments was a LaVision DAVIS with a Twins Ultra Yag $2 \times 30 \mathrm{~mJ}$ Laser (wave peak $532 \mathrm{~nm}$ ). The camera (ProX2M) with a minimum interframe of 110 ns was used to record PIV-LIF images. The laser was passed through a lens which shaped the resulting beam into a light sheet. The delay between two pictures was of $120 \mu$ s. The field of view was $232 \mathrm{~mm} \times 150 \mathrm{~mm}$ and included the downcomer centre. Consequently, 150 double image pairs were obtained in each assay, and were considered to be sufficient to obtain statistics results. Each assay was performed in triplicate.

\section{Results and discussion}

\subsection{Optical probe application in $g-l-s$ systems with spent grains}

The solids used in this work (spent grains) have the ability, when in the presence of water, to form aggregates especially in the sections of the reactor (conical part) where the liquid velocity is lower (dead zones): this behaviour results from their hydrophobic surface and rugosity. These particles and bubbles have similar sizes ( $1 \mathrm{~mm}$ to $5 \mathrm{~mm}$ ) so the tip can pierce one or more particles that are flowing upwards in the riser. The pierced particles will then interact with the moving particles and agglomeration around the optical tip is observed. When this agglomeration is high enough the optical probe signal is equal to the liquid-phase signal, which means that no bubbles are detected.

The application of optical probes in $g-l-s$ systems is scarce and limited to low solids content. The main reason is the risk of optical fibre contamination, which depends mainly from the solids properties and size. In general solid properties are such that they have no influence in optical probe signal, but there are exceptions. Mena and co-workers (2008) evaluated the optical probe signal with different solid materials such as: glass, polystyrene and alginate beads. They found that alginate beads, a semi-rigid solid, let some residues after tip-solid interaction and high voltage signals were observed: without a proper signal processing the later could be misinterpreted as alginate beads detection instead of bubbles detection (Mena et al., 2008).

The contamination caused by solids agglomeration around the tip is a different type of contamination from the one reported by Mena et al. (2008). The particle agglomeration avoids bubble-tip interaction and it is not possible to accurately measure the bubbles' properties. To overcome this problem it was implemented an injection system that acts periodically near the probe tip. To perform this task, the optical probe was fixed inside a stainless steel hand-made structure where three needles were placed (Fig. 1). Water was injected through these needles ( 7 in Fig. 1 ) in order to create a flow around the probe tip (10 in Fig. 1). This water flow cleaned the probe tip ( 9 in Fig. 1) and allowed tip-bubble interaction.

The cyclic injection (Injection time(s)/Total cycle time(s) $=0.5 /$ 2.5) was performed by using one electro-valve (Sirai, Milan, Italy) controlled by a PC equipped with LABVIEW (National Instruments, Austin, Texas, USA). The signal acquisition of the electro-valve and optical probe were recorded using an acquisition board NI BNC2110 (National Instruments, Austin, Texas, USA) and LABVIEW program, which saves the signal in a binary file per assay. Then each file was treated using MATLAB 6.1 (MathWorks, Natick, MA, USA) program, developed to read the binary files. The same program was used to determinate all characteristic points from the optical probe signal $\left(t_{A}, t_{B}, t_{C}\right.$ and $t_{D}$ in Fig. 2$)$, as well as to calculate all gas phase properties: gas holdup, bubble velocity and average chord. The gas holdup is defined from $T_{G}=t_{B}-t_{A}$ as:

$\alpha_{G}=\Sigma T_{G} /($ total acquisition duration)

Bubbles' velocities are calculated from the rising time $T_{U}=t_{D}-t_{C}$ through a calibration curve specific to each probe.

The sampling rate was $10 \mathrm{kHz}$ to ensure a good definition of $T_{U}$ and the duration of each assay was $800 \mathrm{~s}$. Each experimental condition was repeated at least five times in order to have enough measured bubbles $(\geq 1000)$ that assure statistical evaluation.

The liquid-phase periodic injection and the turbulence that it promotes de-contaminates the tip. Nevertheless, there are some drawbacks when injection near the probe is applied because of the induced perturbations that influence probe measurement (Vejražka et al., 2010). In order to properly evaluate the signal with reduced sources of errors it was necessary to develop a specific signal processing that removes some parts of the signal from the optical probe raw feed: these parts correspond to the time intervals when injection influences the measurement. This has been done by comparing the results obtained in a two-phase system using the TGV algorithm (Cartellier, 1992) and a new signal processing algorithm developed for this work. Then, the measurement tool was applied to more a complex $g-l-s$ system. 
A

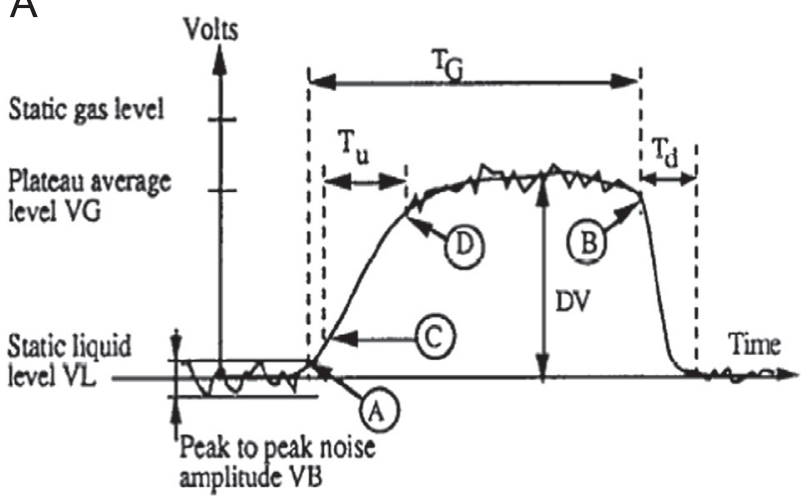

B
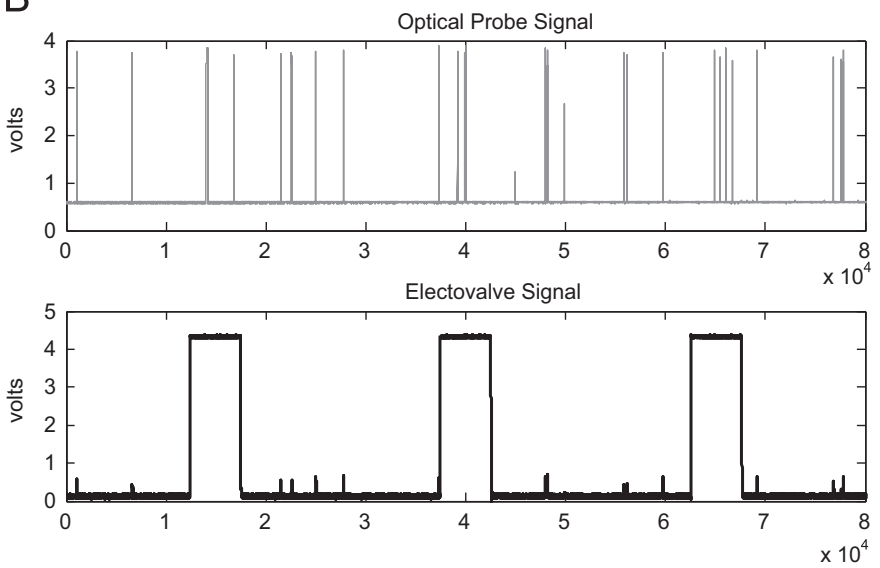

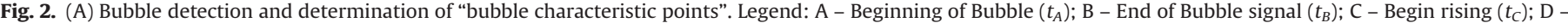

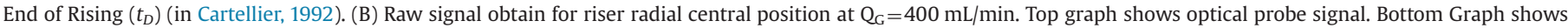
electro-valve signal. (The total time corresponds to $7 \mathrm{~s}$ ).

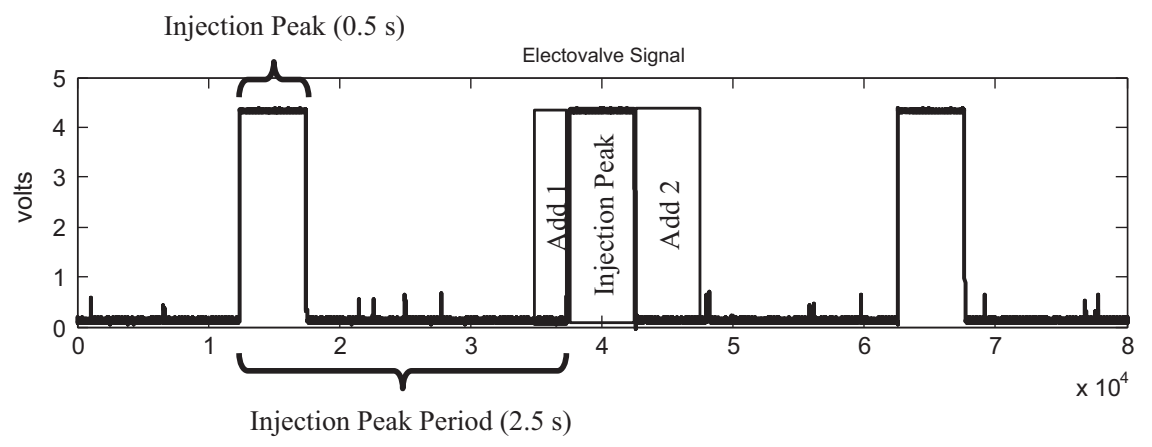

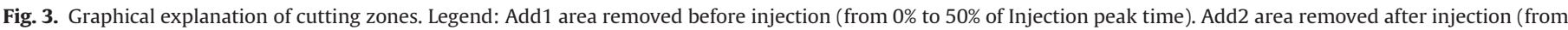
$0 \%$ to $100 \%$ of Injection peak time).

\subsection{New signal processing explanation and validation in $g-l$ configuration}

The injection system developed allows bubble detection and the measurements of their properties using an optical probe in an air-water-spent grains mixture. At lowest gas flow rate the probe tip cleaning was more efficient. This means that the liquid injection energy was strong enough both to counteract the upwards liquid energy and remove the attached spent grains. However, in practical terms the injection system, in its current state, was not

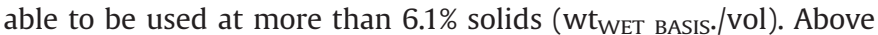
this value, the cleaning system was not able to do an efficient tip cleaning for both gas flow rates tested. The maximum solids concentration was defined as the maximum concentration where no quality bubble information could be collected under the criteria defined: 5 measurements to achieve a minimum sample of at least 1000 bubbles.

The data present in the binary file contains the whole signal. It is then post-processed in order to remove the influence of the injection. Therefore only the data not influenced by the injections are analysed to determine gas-phase properties. A first evaluation of the new system was carried out performing measurements in a $g-l$ system: the new post-processing algorithm was applied to data obtained with the probe equipped with the injection system. Results were compared to data obtained with a probe without injection and the application of the TGV (Treatment of Gaseous Velocities) algorithm (Cartellier, 1998). This algorithm is a real time processing algorithm based on the detection of few bubble characteristic points knowing the signal level for water $\left(\mathrm{V}_{\mathrm{L}}\right)$, gas
$\left(\mathrm{V}_{\mathrm{G}}\right)$, and the noise level $\left(\mathrm{V}_{\mathrm{B}}\right)$ around those levels (Fig. 2). Basically, the signal points are not time-sampled but sampled in terms of signal amplitude difference $(\Delta \mathrm{V})$ between two consecutive points ( $\Delta V$ being a fraction of $\mathrm{V}_{\mathrm{G}}-\mathrm{V}_{\mathrm{L}}$ ). A bubble is first detected when the signal amplitude is above $\left(\mathrm{V}_{\mathrm{L}}+\mathrm{V}_{\mathrm{B}} / 2\right)$. The sampling based on the difference of amplitude allows to get several points in the rising part of the signal (A to D). Then the last detected point is the end of the "plateau", $B$, when the signal goes below $\left(V_{G}+V_{B} / 2\right)$. This real time processing algorithm was initially developed as high sampling frequencies were required to get a good definition of the rising time while the amount of information was useful to completely define the gas presence in the signal as low: it was a way to avoid unnecessary signal storage.

In the case of the probe equipped with the injection system, the raw signal was composed by two curves: one corresponding to the signal recorded by the OP and another corresponding to the signal of the injections (Fig. 2). Contrary to the TGV algorithm, the OP signal was stored and then processed.

At each injection there is a perturbation in the probe and in the flow. This lead to possible measurements errors due to (1) the probe movement, (2) the increased bubble residence time (higher $T_{G}$ ) and (3) bubble deflection. To avoid these errors the signal is then cut before and after the injection and only the remaining signal is used for gas phase properties determination. The cut signal and the gas holdup are then analysed, as well as bubble velocities calculated. The cutting time (defined as a given percentage of the injection duration) becomes one of the critical parameters for holdup determination. The gas holdup was 
therefore calculated using a combination of different cutting zones before and after the injection.

The cutting zones (Fig. 3) include the time when the injection was performed and also fractions of time before and after the injection. Fractions of time before the injection were considered as the electro-valve operation as well as the liquid flow inside the injection tubes (turbulence, pressure waves) induces perturbations on the probe itself. However, considering that for bubble detection, the perturbations due to the flow in the vicinity of the probe tip are more important, the different cutting zones were evaluated as follows: ADD1-up to $50 \%$ less time before the beginning of injection; ADD2-up to 100\% more after the injection time. This means that, per each injection period $(2.5 \mathrm{~s})$, the minimum time removed was $0.5 \mathrm{~s}$ corresponding only to the injection and the maximum time was $1.25 \mathrm{~s}$ corresponding to a cutting of $50 \%$ $(0.25 \mathrm{~s})$ before and $100 \%$ ( $0.5 \mathrm{~s})$ after the injection $(0.5 \mathrm{~s})$ as explained in Fig. 3.

The error between gas holdup measure using the TGV program and using the new method was calculated using the following equation:

$\%$ Error $=\left[a b s\left(x_{T V G}-x_{I N J}\right)\right] / x_{T G V} * 100$
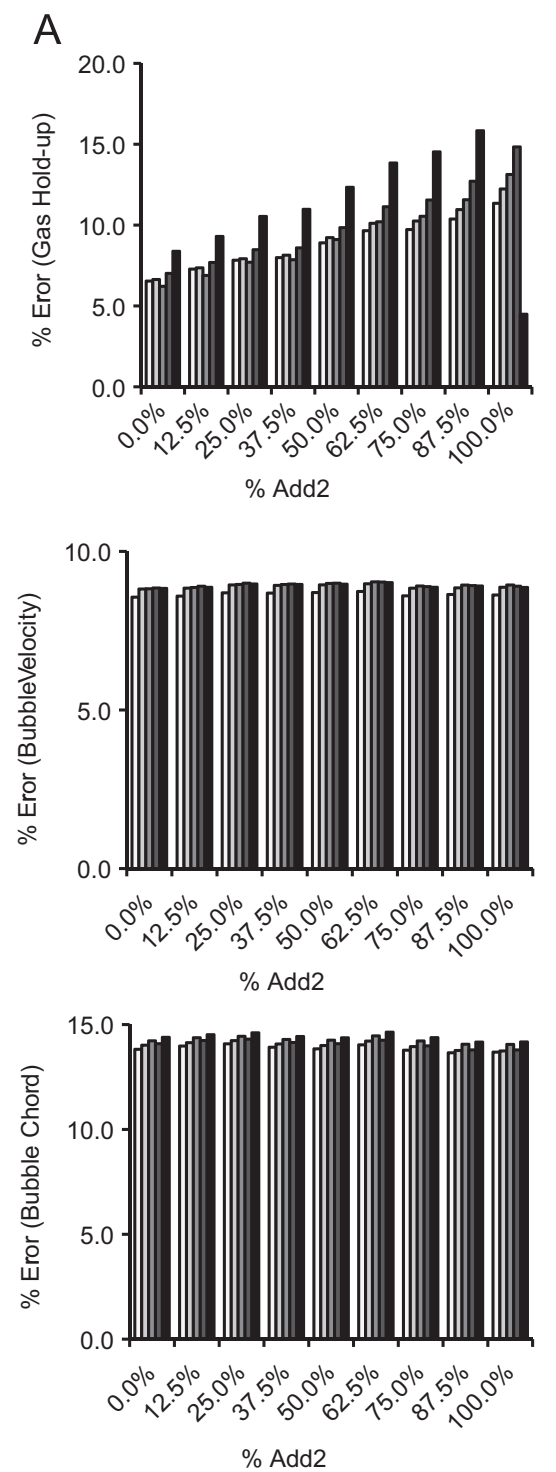

where $x$ represents the gas-phase properties that can be: gas holdup $\left(\alpha_{G}\right)$; bubble velocity $\left(v_{B}\right)$ or bubble chord length $\left(c h_{B}\right)$. The subscript TVG or INJ represents the values obtained in the TVG algorithm (Cartellier, 1998) and in the new processing method respectively.

Being so and before measuring the gas-phase properties in $g-l-s$ systems it was necessary to know the range of cutting zones where the new method is valid. The validation was performed in a $g-l$ system where it is possible to obtain reliable results from the TVG algorithm. Data gathered with a classical probe and analysed with the TGV method were used as a reference. The optimal cutting zone parameters was then defined as the set (or range) of values, where the error between the new and TGV methods was lower. An initial observation indicated that the new system generally overestimates the gas-phase properties for $250 \mathrm{~mL} / \mathrm{min}$, while for $400 \mathrm{~mL} / \mathrm{min}$ the results are underestimated. The relative errors between the two methods are presented in Fig. 4. It is shown that bubble velocity and chord size are not greatly affected by the different cutting zones. However, this does not happen for gas holdup. Strictly speaking, all those quantities are dependent on the number of detected events to achieve convergence. But by definition, the gas holdup is also based on the ratio between the

B
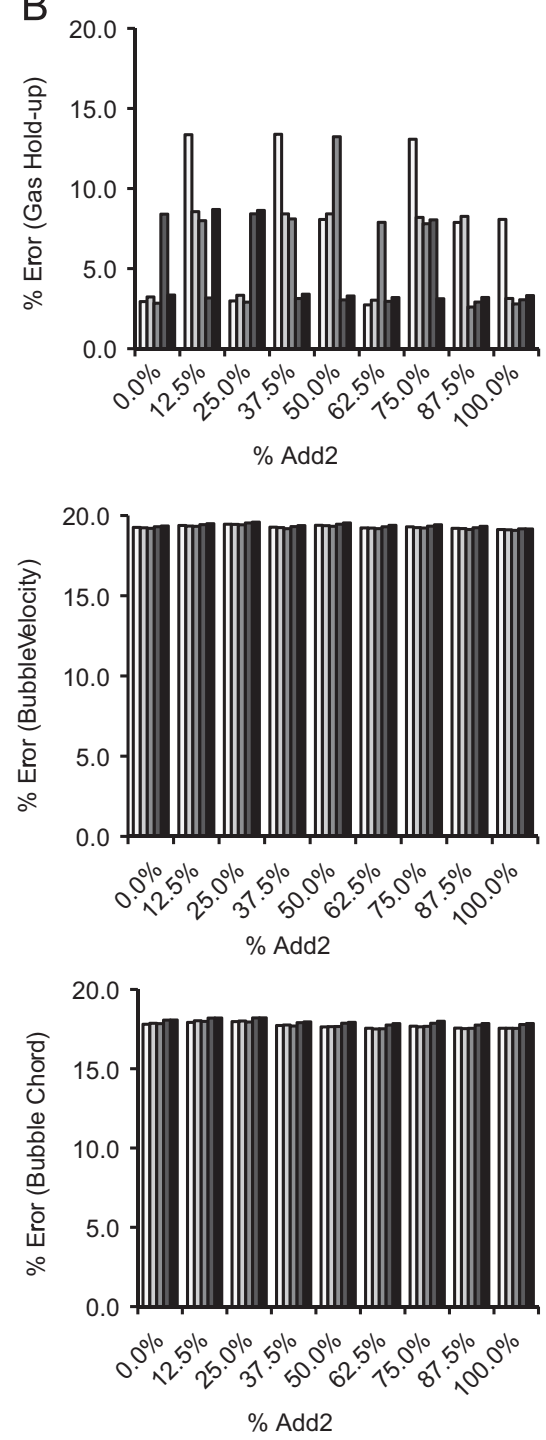

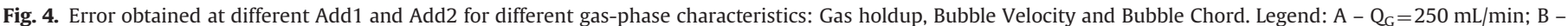
$\mathrm{Q}_{\mathrm{G}}=400 \mathrm{~mL} / \mathrm{min}$; $\square-0.0 \%$ Add1; - $-12.5 \%$ Add1; - 25.0\% Add1; - $-12.5 \%$ Add1; - $-50.0 \%$ Add1. 
total gas residence time at a given point over the total effective sample duration. We can then expect that the gas holdup will be a quantity sensitive to the cutting zone amplitude (Cf. Eq. 1). It was considered that the best cutting zones are the ones where minimal errors between the two methods are obtained. This condition was achieved for $250 \mathrm{~mL} / \mathrm{min}$-Add $1<37.5 \%$ and Add $2<37.5 \%$, and for $400 \mathrm{~mL} / \mathrm{min}-25 \%<\operatorname{Add} 1<50 \%$ and $50 \%<\operatorname{Add} 2<100 \%$. Inside these values the error between both methods for the gas holdup was: for $250 \mathrm{~mL} / \mathrm{min}$ below $10 \%$ and for $400 \mathrm{~mL} / \mathrm{min}$ below $5 \%$. The error for bubble velocity was $10 \%$ and $20 \%$ for $250 \mathrm{~mL} / \mathrm{min}$ and $400 \mathrm{~mL} / \mathrm{min}$ respectively, while for bubble chord the error was 15\% and $20 \%$. We believe that the greatest observed error in bubble properties (velocity and chord) are related with the low frequency acquisition used $(10 \mathrm{kHz})$ when compared with the one used in the TGV method $(50 \mathrm{kHz})$ (Cartellier, 1998). This lower acquisition rate was a technical constraint: the acquisition duration had to be longer to achieve the number of bubbles necessary to reach statistical convergence. With $10 \mathrm{kHz}$, we were almost at the limit of the system memory capacity to store and analyse the signal. This lower acquisition rate may have had an influence on the accuracy of the signal rise times which are used to calculate bubbles' velocities. However, the results were promising enough to validate the method and test it on a more complex flow.

\subsection{Riser gas holdup in $g-l-s$ configurations}

The main results obtained to determine the gas-phase properties in the riser were done using the optical probe system developed above. However, to assess the implementation of the new probe system in these configurations, global gas holdup were also determined using an inverted manometer to measure the pressure drop between two points in the riser (Chisti, 1989). The global gas holdup determined by the pressure drop technique was calculated considering homogeneous solids distribution and according to the following equation:

$a_{G r}=\left(H_{1}-H_{2}\right) / d_{12}-\left(\rho_{L}-\rho_{S}\right) / \rho_{L} * a_{S}$

To check the significant differences between all measurements, the results were statistically evaluated. For each solids concentration, two different gas flows were tested: 250 and $400 \mathrm{~mL} / \mathrm{min}$. Brányik et al. (2004) found that $250 \mathrm{~mL} / \mathrm{min}$ was a good compromise between mixing time, biocatalyst sedimentation, and the maximum immobilization for yeast cells and the choice of that flow rate was governed by the objective of applying this work to industrial configurations.

Initially, radial gas-phase properties were analysed for each condition (different gas flows and solid loads). Preliminary tests showed that no significant differences in the results were detected between the radial positions studied (data not shown). This

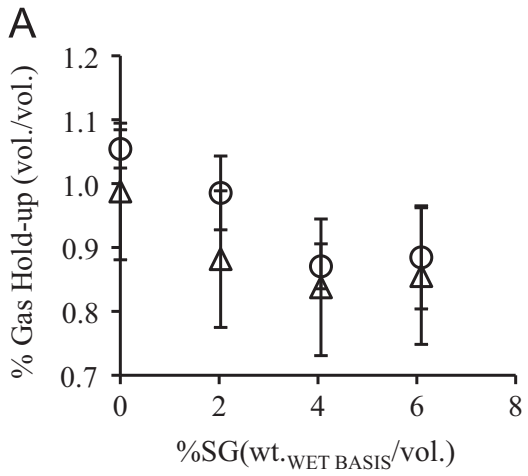

reveals that in the gas-phase a flat profile is present, which was also valid for bubble velocity and chord. According to Deng et al. (2010) the presence of a flat gas holdup profile at $U_{G r} \leq 2 \mathrm{~cm} / \mathrm{s}$ is normal in air-lift reactors riser. Additionally, in the consulted literature, for these configurations, negligible differences in gas holdup profile are reported on the radial position, provided that the measurement is not performed too close to the reactor wall where gas holdup differences are detected (Deng et al., 2010; Mena et al., 2008). As the probed had lower spatial resolution, due to the injection system built around, for the following measurements, local gas-phase properties (gas holdup, bubble velocity and chord)) were measured only in the riser central part.

From Fig. 5, it is possible to verify that global gas holdup decreases with the increase of solid content. The gas holdup decrease is significant with solid loads above $4 \%$ and $2 \%$ (wt WET $_{\text {WET }}$ BASIS $/ \mathrm{vol}$ ) respectively for 250 and $400 \mathrm{~mL} / \mathrm{min}$. At $400 \mathrm{~mL} / \mathrm{min}$ it was not noted any significant difference on gas holdup values among the different solids concentrations. Regarding the results presented in Fig. 5, a similar trend is observed between the optical probe results and the global results from the manometers. This is better seen at $250 \mathrm{~mL} / \mathrm{min}$ than at $400 \mathrm{~mL} / \mathrm{min}$. In general the gas holdup in the riser of iGLR decreases in the presence of solids, being more significant at gas superficial velocities above $10 \mathrm{~cm} / \mathrm{s}$ (Freitas and Teixeira, 1998; Klein et al., 2003). It is important to note that in three-phase iGLR there are a lot of different mechanisms that may influence gas holdup (design, type of solids and operational conditions) and the impact of each one of them is not yet clear (Chisti, 1989). Therefore when results are compared with the literature these elements must be taken in account. Nevertheless, the gas holdup results obtained in this work are in agreement with the trends found by other authors when similar solids (size and density) are present (Freitas and Teixeira, 1998; Klein et al., 2003), and they are also in the same range reported by many other authors who worked with two- and three-phases iGLR configuration using different measurement methods (Albdiri et al., 2014; Luo and Al-Dahhan, 2010).

The presence of solids modify the way bubbles interact with the probe: the source of uncertainties may then change with the solids loading and this must be taken into account when results are compared to global measurement. At $400 \mathrm{~mL} / \mathrm{min}$, for instance, it is observed that when no solids are present the gas holdup from the optical is overestimated, while the opposite occurs when suspended solids are present. When solids are present the underestimation may be due to blinding and drifting effects. This blinding effect is related with the solids size and properties. The tested solids are in the same size range than bubbles, therefore the interaction between them is high. These solids induce small change in bubbles direction, especially small bubbles, and consequently bubbles interaction with the probe is affected, especially

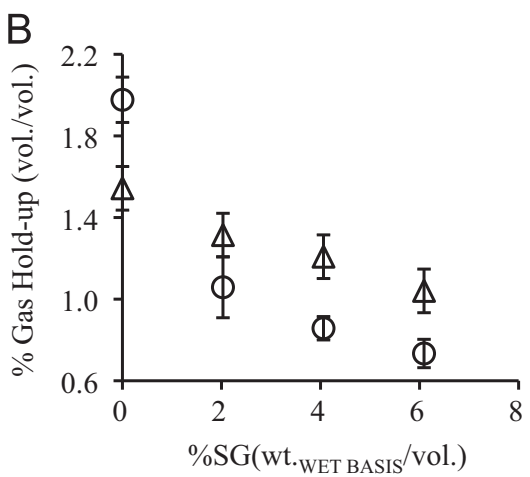

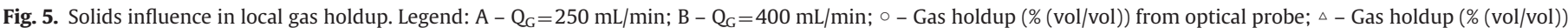
from manometers. 
during the tip contamination process. The solids may then lead to a non-detection of small bubble chord, which can result in underestimation of the local gas holdup. In addition, when fully contaminated with spent grains the signal probe is equal to water signal and no bubbles are detected. But we expect that these extreme conditions are avoided through the cleaning process and signal analysis.

Besides these phenomena, uncertainties between the two methods remain acceptable and in the range of those given by Cartellier (1992). It was also verified for other geometries such as bubble column (Mota et al., 2011), that the gas holdup decreased with the concentration of spent grains increase.

For all the reasons mentioned above, it is plausible to consider that the results for gas holdup using the OP in three-phase systems with the new injection system are consistent and reliable. Considering that this system is far from being totally developed it is still possible to obtain viable results for low spent grains concentration $\left(<6 \%\left(\mathrm{wt}_{\text {WET BASIS }} / \mathrm{vol}\right)\right.$.

\subsection{Bubbles' properties: velocity and size}

On a physical point of view, the decrease of the gas holdup in presence of solids is often interpreted as an increase of the bubbles' relative velocity via the coalescence phenomena (Mena et al., 2008).

In order to further assess our measurement technique, the measured data were also investigated in terms of bubble size and velocities as the customized probe developed for this work allows such measurement. To be able to measure gas holdup and bubble characteristics parameters simultaneously in a $g-l-s$ system constitutes an originality of this work.

The results showed that in our case the chord size and velocity seems to increase as soon as solids are added to the flow (Fig. 6) before reaching a plateau. Similar results were found when an identical optical fibre was used and tested with alginate beads (Mena et al., 2008). However, chord size increase alone is not directly related with a bubble size increase because bubble shape and sphericity can also change (especially between the $g-l$ configuration and $g-l-s$ configuration). In particular, the derivation of the real bubble size distribution from the chord distribution is not an easy task. It requires assuming a specific flow structure (Mena et al., 2008, Cartellier et al., 1999) and even for the academic case where the bubbles are almost spherical, with a narrow size distribution and an homogeneous regime, the problem remains complex (Cartellier and Achard, 1991).

That is why, in order to get a better understanding of the underlying physical mechanisms involved in the chord size and velocity increase, as well as to assess the OP data measurements, data were also obtained using the HSC technique. When image analysis is applied to determine bubble properties in $g-l-s$ systems, it is only possible to use automatic thresholding or segmentation methods if the grey level between solids and bubbles is different enough (Mena et al., 2005a). In our case the spent grains limited the use of automatic methods on the images, because their grey level was similar to bubbles' grey level. That made it more difficult to distinguish between bubble and particle (see Fig. 7). That is why only low solids concentration ( $\leq 2 \%$ ( $\mathrm{vol} / \mathrm{vol})$ ) were tested.

The images and videos obtained with the HSC were used to determine bubble velocity and bubble chord (manually and following bubbles frame by frame). When spent grains particles are present the analysis of the images is more difficult, even using the manual methods and maintaining the same criteria. For these cases the "noise" caused by the presence of solids in the image affects the identification of bubble boundary and therefore the determination of chord size. For the bubble velocity determination using the HSC, the bubble reference point used was the bubble central point, which reduces the measurement error even in the presence of solids. The results between HSC and optical probe techniques for the lowest gas flow at 0 and $2 \%\left(\mathrm{wt}_{\mathrm{WET}}\right.$ BASIS $\left./ \mathrm{vol}\right)$ solid load are presented in Fig. 6 (along the OP probe measurement) and in Table 1. Those results allow the estimation of the
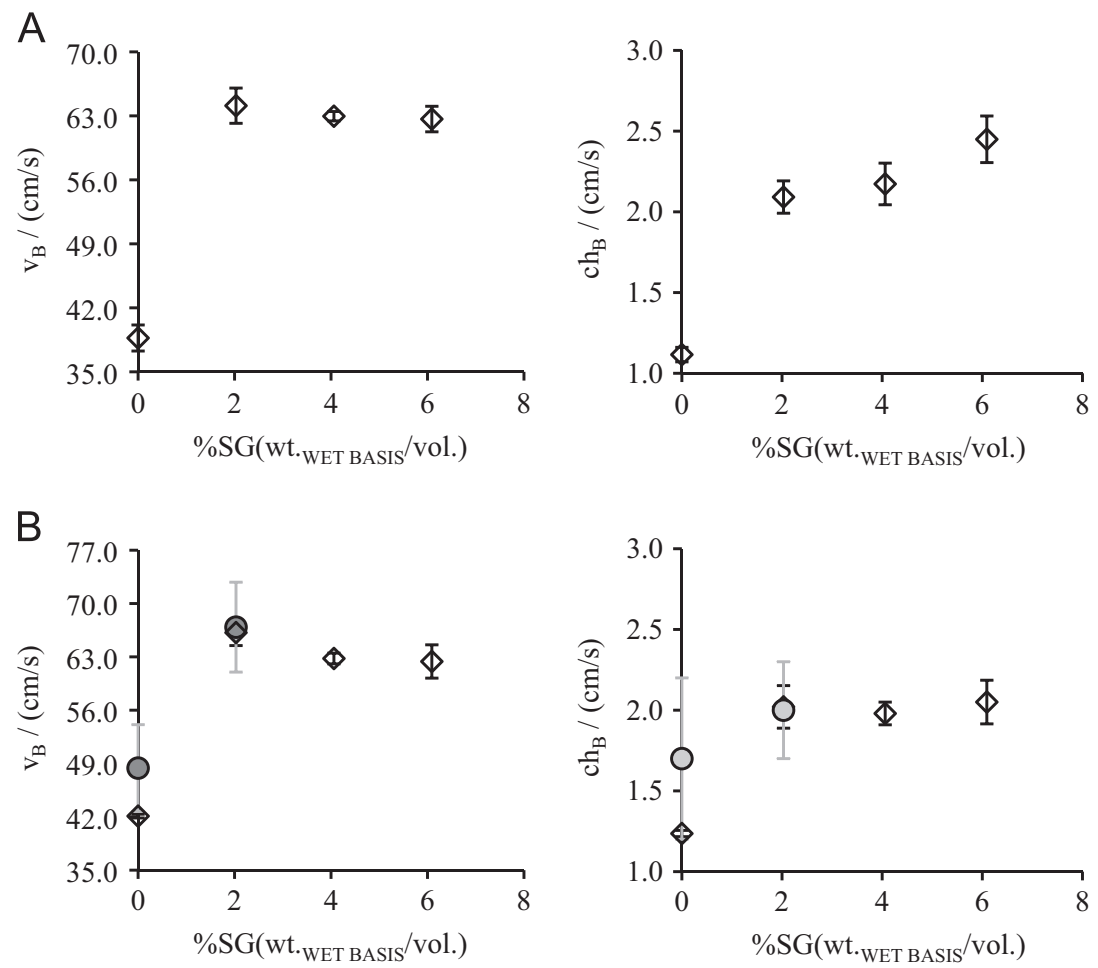

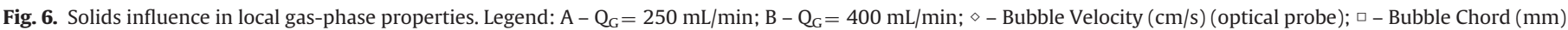
(optical probe); ○: HSC measurements. 

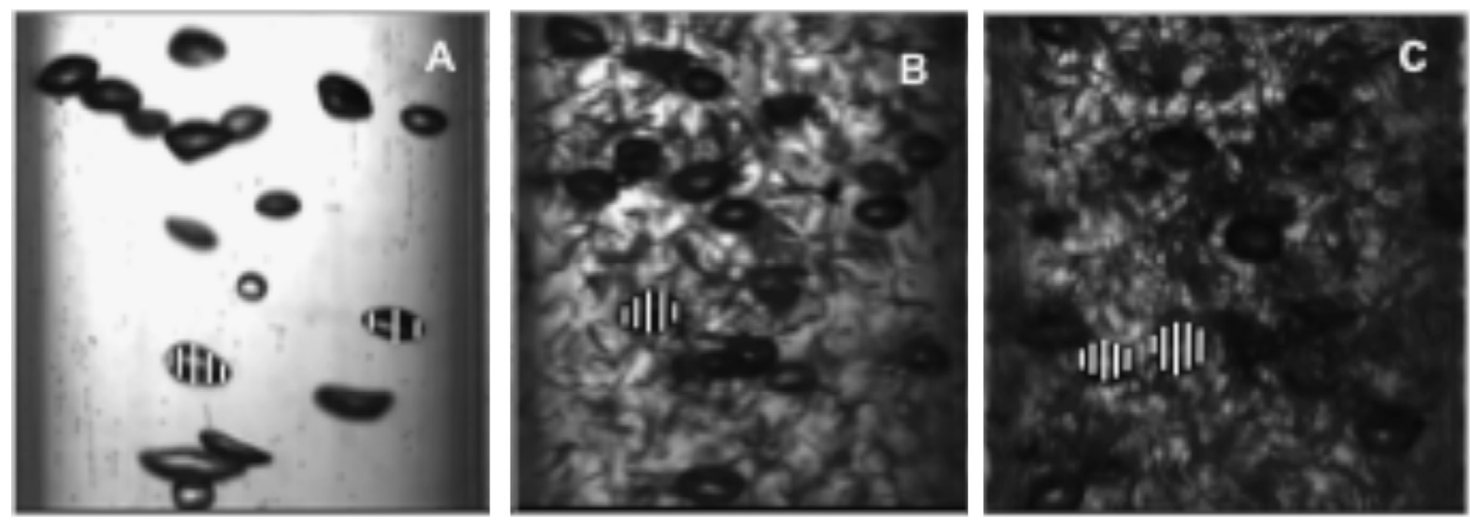

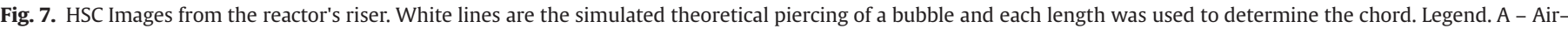
Water; B - Air-Water-SG (0.8\% (wt WET BASIS $\left._{\text {Vol }}\right)$ ); B - Air-Water-SG (2\% (wt WET BASIS $\left._{\text {vol }}\right)$ ).

Table 1

Results of evaluation by OP and HSC for $Q_{G}=400 \mathrm{~mL} / \mathrm{min}$.

\begin{tabular}{|c|c|c|c|c|}
\hline \multirow[t]{2}{*}{$\begin{array}{l}\text { Gas phase } \\
\text { properties }\end{array}$} & \multicolumn{2}{|l|}{ Air-water } & \multicolumn{2}{|c|}{$\begin{array}{l}\text { Air }-\left[\text { water }+2 \% \text { SG ( } \text { wt }_{\text {wet basis }} /\right. \\
\text { vol)] }\end{array}$} \\
\hline & HSC & OP & HSC & OP \\
\hline $\begin{array}{l}\text { Bubble velocity } \\
(\mathrm{cm} / \mathrm{s})\end{array}$ & $48.4 \pm 5.7$ & $44.3 \pm 7.5$ & $66.9 \pm 5.9$ & $64.8 \pm 5$ \\
\hline $\begin{array}{l}\text { Bubble chord } \\
(\mathrm{mm})\end{array}$ & $1.7 \pm 0.5$ & $1.3 \pm 0.3$ & $2 \pm 0.3$ & $2.1 \pm 0.4$ \\
\hline
\end{tabular}

Table 2

Sauter Diameter and Bubble Sphericity from HSC measurements.

\begin{tabular}{|c|c|c|c|c|c|}
\hline \multirow[t]{2}{*}{$\begin{array}{l}\text { \% Solids (wt.wET } \\
\text { BASIS/vol.) }\end{array}$} & \multirow[t]{2}{*}{$\begin{array}{l}Q_{\text {AIR }} \\
(\mathrm{mL} / \mathrm{min})\end{array}$} & \multicolumn{2}{|c|}{$\mathrm{D}_{32}(\mathrm{~mm})$} & \multicolumn{2}{|c|}{$\begin{array}{l}\text { Sphericity } \chi \text { (minor axe/ } \\
\text { major axe) }\end{array}$} \\
\hline & & MIA & AST & MIA & AST \\
\hline \multirow[t]{2}{*}{0} & 250 & 3.82 & 3.86 & 0.599 & 0.564 \\
\hline & 400 & 3.96 & 3.90 & 0.598 & 0.586 \\
\hline \multirow[t]{2}{*}{0.8} & 250 & 3.62 & 3.43 & 0.588 & 0.563 \\
\hline & 400 & 3.86 & NP & 0.576 & NP \\
\hline \multirow[t]{2}{*}{2.0} & 250 & 3.80 & NP & 0.625 & NP \\
\hline & 400 & 3.72 & NP & 0.620 & NP \\
\hline
\end{tabular}

$\mathrm{NP}$ - Not possible to evaluate by the program due to bad image quality.

uncertainties between the two methods. It shows that there is no significant difference between the two methods concerning velocities: between the optical probe measurements and the visualization technique the discrepancy obtained for bubble velocity was between -3 and $-9 \%$ respectively for 0 and $2 \%$ ( $w_{\text {WET BAsIs }} / \mathrm{vol}$ ) solid load. Concerning bubble chords, uncertainties range from $-24 \%$ to $5 \%$. The worst uncertainty corresponds to the $g-l$ flow but as the chord size is affected by the uncertainties both on the bubble residence time and velocity, we can expect more discrepancies on these results than for the other parameters. These uncertainties ranges are consistent with those given by Cartellier (1992) who found discrepancies between $+13 \%$ and $-24 \%$ for bubble velocity and size respectively in a two phase flow. Even if the evaluation of the results in $g-l$ and $g-l-s$ systems could be performed only for a small fraction of solids ( $2 \%(\mathrm{vol} / \mathrm{vol})$ ), it gives an insight on the relative performance of the OP readings. Bubble size and shape evolution is also given in terms of Sauter diameter and sphericity $\chi$ (defined as the ratio of the bubble minor axe over the bubble major axe) in Table 2 for the HSC measurements (both from manual measurements - MIA - or the automatic statistic tool (AST) developed by Ferreira et al. (2012). Those measurements show that the bubble size and shape do not change that much.

\subsection{Data consistency through liquid/solid properties measurement and the drift flux model}

To go further concerning the data validation, the bubble relative velocity and its evolution with the solid loading was estimated using complementary data on the liquid and gas phase in a model based on the drift flux formulation. In the model, the unknown is the relative velocity and the model entries are the mean velocity of the gas and solid-liquid mixture, the measured linear gas velocity and gas holdup.

Liquid velocity profiles measured through PIV are presented in Fig. $8 \mathrm{~A}$ and B. From this figure, it is possible to observe that the liquid velocity profile in the downcomer is higher at central position between riser and downcomer than near the column wall $(r=1.5 \mathrm{~cm})$. These results were only obtained in the outer part of the downcomer. For simplification, in this assay the profile in the inner part was assumed to be symetrical.

In this case, the study was focused on the downcomer and using the images from HSC, the average solid velocity in the downcomer was manually determined. Due to visualization limitations only the lowest solid concentration $\left(2 \%\left(w_{\mathrm{WET}}\right.\right.$ BASIS $\left.\left./ \mathrm{vol}\right)\right)$ was evaluated. In these conditions spent grains average velocity in the downcomer was of $9.1 \mathrm{~cm} / \mathrm{s}$ and $11.1 \mathrm{~cm} / \mathrm{s}$ respectively for gas flow rates $250 \mathrm{~mL} / \mathrm{min}$ and $400 \mathrm{~mL} / \mathrm{min}$. These velocities can be compared to the average liquid velocity in the downcomer for both gas flowrate (Fig. 8C and D) for the same solids loading. The solids velocity increase observed with the gas flowrate is similar to the increase observed for the liquid phase. In fact, solid and liquid average velocities are nearly the same. This result made us assume a pseudo-homogeneous phase for the liquid-solid mixture, at least at low solid content. This result is consistent with a previous study which showed that for this configuration the solids distribution is almost constant even at low gas flows (Klein et al., 2003). So it was considered in this work that solids holdup and distribution are homogeneous throughout the entire iGLR. Fig. 8C and D shows also that the influence of spent grains in the average liquid velocity in the downcomer is negligible for a gas flowrate equal to $400 \mathrm{~mL} / \mathrm{min}$ whereas a small decrease in liquid velocity is present at $250 \mathrm{~mL} / \mathrm{min}$. This is a mere indication that solids increase the stability of the flow in downcomer. In a limit situation, if the amount of solids is significantly increased, no circulation would be observed because the gas flow would not be enough to fluidize all solids. This is in accordance with previous results present in the literature (Freitas, 2002).

From the measurement above, a quantitative analysis of the data consistency is now possible using a model based on the driftflux formulation (Chisti, 1989; Lu et al., 1995). Indeed, from the drift-flux concept, it is possible to write the following equation 

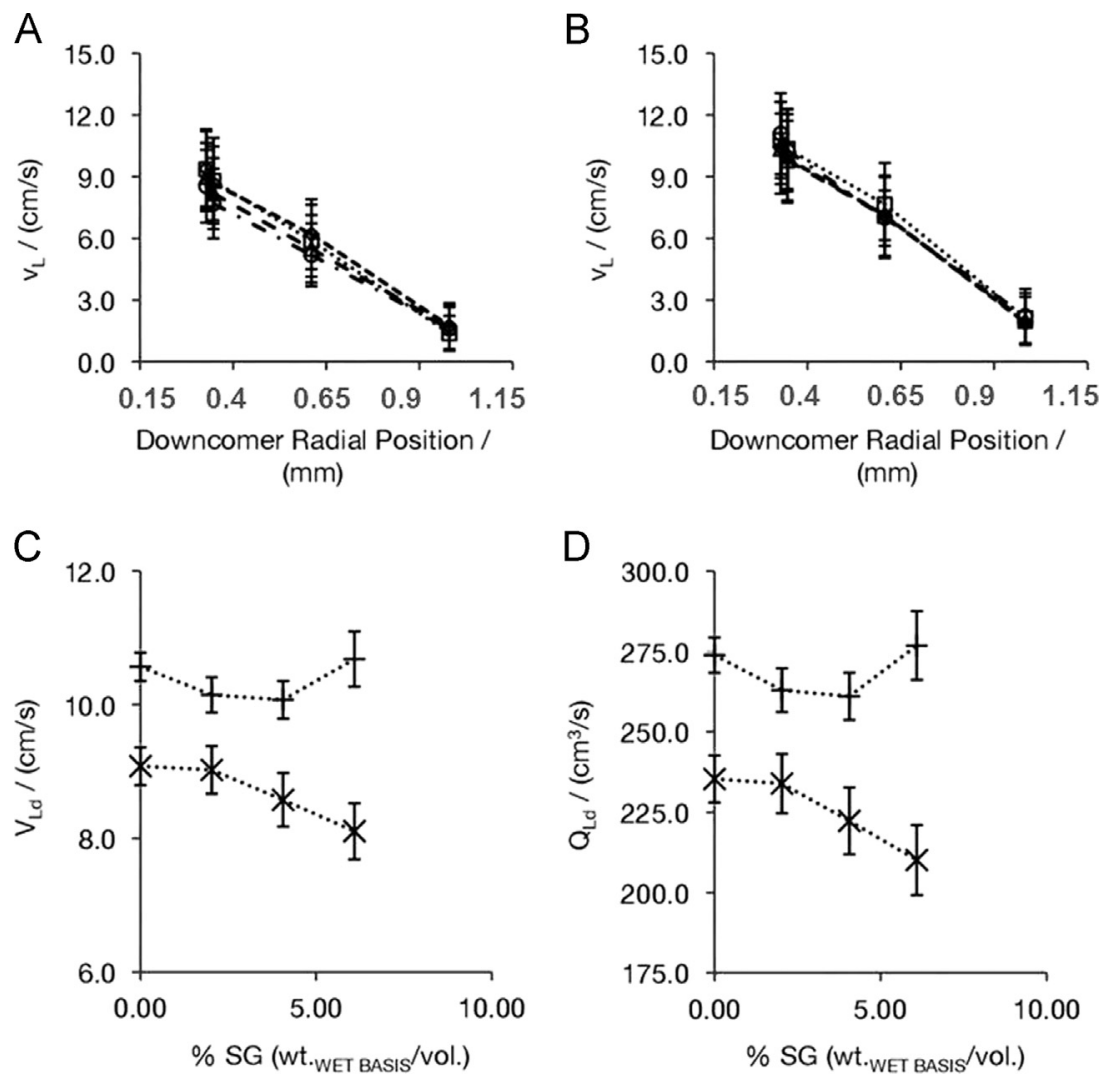

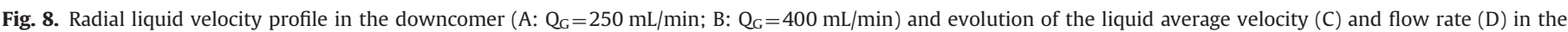

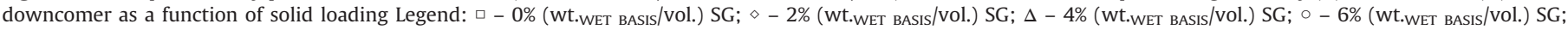
$\mathrm{x}-Q_{\text {AIR }}=250 \mathrm{~mL} / \mathrm{min}$ (in C and D); $+-Q_{A I R}=400 \mathrm{~mL} / \mathrm{min}$ (in C and D).

written for the riser:

$v_{G r}=C *\left(U_{G r}+U_{H r}\right)+\left(1-\alpha_{G}\right) * U_{r}$

where $\mathrm{v}_{G r}$ is the linear gas velocity in the riser, $U_{G r}$ the superficial gas velocity, $U_{H r}$ the pseudo-homogeneous phase superficial velocity, $\alpha_{G}$ the gas holdup and $U_{r}$ the relative velocity between the gas and the homogeneous phase). $C$, the distribution factor was assumed to be equal to 1 (that is to say a flat profile for both phases). Furthermore, according to the solid and liquid velocity measurements in the downcomer, it was assumed that the liquid superficial velocity for the pseudo-homogeneous phase was also equal to the liquid superficial in the riser. Those assumptions have been checked from applying the complete model to experiments and fitting unknown parameters to the available data. This calculation is not shown in order to not weigh down the paper.

In Eq. (4), all the quantities are known: the gas flowrate is fixed so the gas superficial velocity is known. The liquid superficial velocity is calculated from the flowrate determined in the riser (Fig. 8D). $\alpha_{G}$ was measured. $\mathrm{v}_{G r}$ can be calculated using the equation $\mathrm{v}_{G r}=U_{G r} / \alpha_{G}$ or the measured bubble velocity can be directly used. Then the relative velocity $U_{r}$ can be calculated. Results are presented in Table 3. The value of $\alpha_{G}$ are those measured by the optical probe or the manometer. The value of $\mathrm{v}_{G r}$ was calculated as: $\mathrm{v}_{G r}=U_{G r} / \alpha_{G}$.

It can be seen that the bubble relative velocity increases with the solid loading. This increase is more pronounced at the higher gas flowrate. The increase of the relative velocity is consistent physically with the observed decrease in gas holdup, and gives weight to the data consistency. Let us also notice that the order of magnitude of the relative velocities are qualitatively coherent with the observed terminal velocity of isolated bubbles in the range of bubbles' size considered here (in Fig. 7.3 from Clift et al., (1978).
Table 3

Liquid superficial velocity and bubble relative velocity according to Eq. (4) as a function of solid volume fraction.

\begin{tabular}{|c|c|c|c|c|c|c|c|}
\hline \multirow{2}{*}{$\begin{array}{l}\mathbf{Q}_{\mathrm{Gr}} \\
(\mathrm{mL} / \\
\mathrm{min})\end{array}$} & \multirow[t]{2}{*}{ \% solids } & \multirow[t]{2}{*}{$\mathbf{U}_{\mathrm{Gr}}(\mathrm{m} / \mathrm{s})$} & \multirow[t]{2}{*}{$\mathbf{U}_{\mathbf{L r}(\mathbf{m} / \mathbf{s})}$} & \multicolumn{2}{|c|}{ Optical probe } & \multicolumn{2}{|c|}{ Manometer } \\
\hline & & & & $\alpha_{\mathrm{G}}$ & $\begin{array}{l}\mathbf{U}_{\text {relCAL }} \\
(\mathbf{m} / \mathbf{s})\end{array}$ & $\alpha_{\mathrm{G}}$ & $\begin{array}{l}U_{\text {relCAL }} \\
(\mathbf{m} / \mathbf{s})\end{array}$ \\
\hline \multirow[t]{4}{*}{250} & $\mathbf{0}$ & 0.0059 & 0.333 & 0.0105 & 0.23 & 0.0098 & 0.27 \\
\hline & 2 & & 0.324 & 0.0098 & 0.27 & 0.0088 & 0.34 \\
\hline & 4 & & 0.302 & 0.0087 & 0.37 & 0.0084 & 0.40 \\
\hline & 6 & & 0.279 & 0.0089 & 0.38 & 0.0086 & 0.40 \\
\hline \multirow[t]{4}{*}{400} & $\mathbf{0}$ & 0.0094 & 0.387 & 0.0198 & 0.08 & 0.0154 & 0.22 \\
\hline & 2 & & 0.365 & 0.0105 & 0.53 & 0.0131 & 0.35 \\
\hline & 4 & & 0.355 & 0.0086 & 0.73 & 0.0121 & 0.42 \\
\hline & 6 & & 0.368 & 0.0073 & 0.92 & 0.0104 & 0.53 \\
\hline
\end{tabular}

For the lower gas flowrate, results are consistent whether the gas holdup values are taken from global measurements or OP probe. The discrepancies are however higher for the highest gas flowrate. It is expected as the calculation of $\mathrm{v}_{G r}$ in the model is highly sensitive to uncertainties on $\alpha_{G}$ (see Section 3.2) and that at a higher flowrate, bubble/bubble or bubble/solid interactions may enhance binding or drifting effect. However, besides these uncertainties, the general behaviour of the parameter measured with the OP seems qualitatively and quantitatively relevant.

\subsection{Results interpretation}

All the complementary measurements techniques used here seem to confirm that the addition of spent grain promotes an increase of the bubbles absolute velocity as soon as the solid is 
added in the flow. This behaviour seems related to an increase of the relative velocity.

In terms of bubble size, the interpretation is less obvious given the uncertainty at $0 \%$ solid fraction for the chord measurements. If OP measurement seems to indicate an increase of the mean chord size between the $g-l$ flow and $g-l-s$ flow, the pictures analysis favour a scenario where the bubbles' size and shape do not change (Table 2. this can be confirmed by visual inspection: see image samples Fig. 7). Those behaviours must now be related to the diminution of the gas holdup as well as the observed change in bubble relative velocity in regards to the solid contents.

Spent grains are completely wettable solids but whose surface are mainly hydrophobic (Brányik et al., 2004). It was observed that completely wettable particles were found to increase gas holdup (Jamialahmadi and Muller-Steinhagen, 1991) and that the increase of hydrophobic particles leads to a bubble swift from small to bigger (Van der Zon et al., 2002). For this later case, hydrophobic particles would act in a $g-l$ interface reducing the energy barrier to film rupture and consequently coalescence would be promoted (Van der Zon et al., 2002). Coalescence was indeed the interpretation given by (Mota et al., 2008) and (Mena et al., 2010) for a g-l-s system using an alginates bed). None of these observations may explain the current measurements.

Indeed, although the gas holdup decreases with the addition of solids, that measurement does not come along a drastic change in the bubble size. So the assumption of coalescence fails to explain our observations.

The bubble size range observed in the present work, Tomiyama et al. (2002) demonstrated also that the bubble relative velocity showed high discrepancies and was highly sensitive both to bubble shape and initial release conditions at the sparger (via contamination effect or other phenomena as depicted in Fig. 7.3 from Clift et al., (1978)) However, here, surface contamination must also be excluded as literature data (in Fig. 7.3 from Clift et al., (1978) shows that contamination usually decreases bubble relative velocity.

In our opinion, our measurements could be further explained by a phenomena of clustering. Such clusters were observed in $g-l$ bubble column: Ferreira et al. (2012) showed the existence of more or less complex clusters of bubbles depending on the operating conditions. These bubble clusters could affect the flow behaviour. The complexity of the bubble system is defined by these authors using the Bubble Complexity Degree $\left(B_{C D}\right)$. This parameter is defined from image analysis: an algorithm considers the probability of a bubble to belong to a single (individual bubbles), medium (bubbles grouped in two) or large complexity system (groups of three or more bubbles) (Ferreira et al., 2012). The Bubble Complexity Degree of an individual bubble is then defined as:

$B_{C D i}=100\left(P b_{i, S}++3 / 2 * P b_{i, M C}++2 * P b_{i, L C}-1\right)$

where $P b_{i, S,} P b_{i, M C}$ and $P b_{i, L C}$ are the probabilities of each bubbles (i) being a single bubbles or (ii) belonging to a medium complexity or large complexity group respectively

The mean complexity degree of the entire population $B_{C D}$ is calculated through the following equation:

$B_{C D}=\frac{1}{n} \sum_{1}^{n} B_{C D i}$

where $n$ is the total number of bubbles

Applying the statistical tool developed by Ferreira et al. (2012) to our HSC images for a very low solid content $\left(0.8 \%\right.$ ( $w t_{\text {WET BASIS }}$ ) vol)) it was noticed that the $B_{C D}$ value increased (so the number of clusters, or number of bubbles in clusters) when solids where added to the iGLR (data not published). Due to the complexity of image segmentation when spent grains concentration increases, it was not possible to use this tool for all solid loads however the results suggested an increase of complexity in the system when solids were added (Ferreira et al., 2012).

As the solids and the bubble size are of the same order, the increase in the relative velocity could be due to steric effect, the bubble path being constraint by a more or less dense network created by spent grains. Because of the uncertainties on the relative velocity values and depending on the reference values (manometer or OP) taken for the gas holdup presented in Table 2 , it is not clear yet if those clusters could be mainly a consequence of the gas flow rate increase alone (as observed in Ferreira et al. (2012) for bubble columns) or if the presence of solids enhance that phenomena.

\section{Conclusions}

A new system based on the customization of an existing optical probe (equipped with a cleaning system using a periodic injection) and a new signal processing algorithm was developed in order to perform simultaneous measurement of the gas holdup, bubble size and velocity in a gas-liquid-solid airlift (with spent grains as solids) at various solids concentrations. The solids specificity was its tendency to create agglomerates around the probe tip. This measurement tool was then assessed through different complementary analysis and measurement techniques in order to test its feasibility and possible application in industrial systems where the slurry conditions can affect the bubbles' behaviour. In particular, the new optical probe system proves itself useful in a $g-l-s$ flow to get information on the gas phase behaviour. In term of gas holdup comparison with global measurement (based on pressure drop measurement) showed that the gas holdup evolution presented a similar trend, that is to say a decrease when the solid concentration increased. Those measurements were completed with bubble characteristics measurements (velocity and chords) both with the probe but also with a High Speed Camera. The uncertainties between the two methods remained acceptable given the known uncertainties for optical probes in $g-l$ flows. Both systems showed qualitative agreement for the system behaviour, namely, a sharp increase of the bubbles' absolute velocities as soon as solid was added along the decrease of the gas holdup. For bubbles size, given the source of uncertainties for the OP (which comes both from the velocity measurement and bubble residence time on the probe) the HSC measurement seems to indicate that bubble size is not affected.

The measured data were then used in a model based on a driftflux formulation: this allowed us to estimate the gas relative velocity behaviour. In particular, the model predicts a relative velocity increase with the gas flow rate and solid content which is physically consistent with the decrease measured for the gas holdup. Although the specific uncertainties associated with the optical probe technology (especially for the velocity measurement which is sensitive to the probe tip de-wetting), the new probe seems reliable to get information from a gas-liquid-solid system involving solids which can aggregate (such as the yeast extract used in this paper, or other fibrous material found in the pulp and paper industry for instance). These findings are not only in term of gas holdup, but also bubble size evolution and gas phase dynamics. In the current state, it is a promising tool to study such systems since they are widely encountered in the industry. This tool remains to be improved however as in the present work it is only a prototype.

The simultaneous analysis of the evolution of the gas holdup, bubble velocity and bubble chord, made us postulate a new behaviour of $g-l-s$ airlift for which the solid surface is hydrophobic: contrary to other studies with other kind of hydrophobic 
solids, we believe that our measurement cannot be explained by coalescence (as the bubble size does not change) but rather by the formation of a bubble cluster. The exact physical mechanism underlying the effect of the spent grain is however difficult to assess from the present measurement even if some assumptions were presented as a possible explanation.

\section{Nomenclature}

\section{Symbols}

A Cross section area $\left(\mathrm{cm}^{2}\right)$

C Distribution factor (dimensionless)

$\mathrm{ch}_{B} \quad$ Bubble Chord ( $\left.\mathrm{mm}\right)$

$d_{12} \quad$ Distance between two riser points (mm)

$d_{e q} \quad$ Equivalent diameter $(\mathrm{mm})$

$\mathrm{H}_{1}-\mathrm{H}_{2}$ Difference of water level in inverted manometer ( $\mathrm{mm}$ )

Q Gas flow rate $(\mathrm{mL} / \mathrm{min})$

$r \quad$ Radial position of the probe

Re Reynold number (dimensionless)

$t_{A} \quad$ Time when the signal from OP is above the noise before $t_{C}(\mathrm{~s})$

$t_{B} \quad$ Time when the signal from OP starts declining (s)

$t_{C} \quad$ Time when the signal from OP starts rising (s)

$t_{D} \quad$ Time when the signal from OP reaches maximum value (s)

$T_{G} \quad$ Time that tip was in contact with gas $(s)$

$T_{U} \quad$ Rising time (s)

$U_{G r} \quad$ Injected gas superficial velocity $(\mathrm{cm} / \mathrm{s})$

$U_{G r} \quad$ Superficial gas velocity in $\operatorname{riser}(\mathrm{m} / \mathrm{s})$

$U_{H r} \quad$ Pseudo-homogeneous phase superficial velocity in riser $(\mathrm{m} / \mathrm{s})$

$U_{\text {rel }} \quad$ Relative velocity $(\mathrm{cm} / \mathrm{s})$

$v_{B} \quad$ Bubble velocity $(\mathrm{cm} / \mathrm{s})$

$v_{G r} \quad$ Linear gas velocity in the riser $(\mathrm{m} / \mathrm{s})$

$x_{I N I} \quad$ Value of gas holdup, bubble velocity/chord using new injection

$x_{T V G^{-}} \quad$ Value of gas holdup, bubble velocity/chord using TGV method

Greek symbols

$\alpha \quad$ Phase holdup (dimensionless)

$\rho \quad$ Specific Weight $\left(\mathrm{kg} / \mathrm{dm}^{3}\right)$

$\chi \quad$ Sphericity

Sub/superscript

$\begin{array}{ll}L & \text { Liquid-phase } \\ G & \text { Gas-phase } \\ S & \text { Solid-phase } \\ r & \text { Riser } \\ d & \text { Downcomer }\end{array}$

\section{Acknowledgements}

The authors gratefully acknowledge the financial support from FCT (Fundação para a Ciência e Tecnologia, SFRH/BD/37082/2007 and SFRH/BPD/45637/2008).

\section{References}

Albdiri, A.D.Z., Ojha, A., Al-Dahhan, M., 2014. Study of local gas holdup and specific interfacial area in a split-column airlift bioreactor using sphosticated 4-point optical probe for culturing microlgae/cyanobacteria. Chem. Eng. Commun. 202, 892-898. http://dx.doi.org/10.1080/00986445.2014.896344.

Boyer, C., Duquenne, A.-M., Wild, G., 2002. Measuring techniques in gas-liquid and gas-liquid-solid reactors. Chem. Eng. Sci. 57, 3185-3215. http://dx.doi.org/ 10.1016/S0009-2509(02)00193-8.

Brányik, T. Vicente, A.A., Machado Cruz, J.M., Teixeira, J.A., 2001. Spent grains-A new support for brewing yeast immobilization. Biotechnol. Lett. 23, 1073-1078.

Brányik, T., Vicente, A.A., Oliveira, R., Teixeira, J.A., 2004. Physicochemical surface properties of brewing yeast influencing their immobilization onto spent grains in a continuous reactor. Biotechnol. Bioeng. 88, 84-93. http://dx.doi.org/ 10.1002/bit.20217.

Cartellier, A., 1998. Measurement of gas phase characteristics using new monofiber optical probes and real-time signal processing. Nucl. Eng. Des. 184, 393-408. http://dx.doi.org/10.1016/S0029-5493(98)00211-8.

Cartellier, A., 1999. Post-treatment for phase detection probes in non uniform twophase flows. International Journal of Multiphase Flow 25, 201-228.

Cartellier, A., 1992. Simultaneous void fraction measurement, bubble velocity, and size estimate using a single optical probe in gas-liquid two-phase flows. Rev. Sci. Instrum. 63, 5442. http://dx.doi.org/10.1063/1.1143416.

Cartellier, A., 1990. Optical probes for local void fraction measurements: characterization of performance. Rev. Sci. Instrum. 61, 874-886.

Cartellier, A., Achard, J.L., 1991. Local phase detection probes in fluid/fluid twophase flows. Rev. Sci. Instrum. 62, 279-303.

Chaumat, H., Billet-Duquenne, A.M., Augier, F., Mathieu, C., Delmas, H., 2005. Application of the double optic probe technique to distorted tumbling bubbles in aqueous or organic liquid. Chem. Eng. Sci. 60, 6134-6145. http://dx.doi.org/ 10.1016/j.ces.2005.04.018.

Chisti, M., 1989. Airlift Bioreactors. Elsevier Science Publishers LTD, Essex (1st ed.).

Clift, R., Grace, J.R., Weber, M.E., 1978. Bubbles, Drops, and Particles. Academc Press Inc, New York (1st ed.).

Deng, Z., Wang, T., Zhang, N., Wang, Z., 2010. Gas holdup, bubble behavior and mass transfer in a $5 \mathrm{~m}$ high internal-loop airlift reactor with non-Newtonian fluid. Chem. Eng. J. 160, 729-737. http://dx.doi.org/10.1016/j.cej.2010.03.078.

Ferreira, A., Pereira, G., Teixeira, J.A., Rocha, F.A., 2012. Statistical tool combined with image analysis to characterize hydrodynamics and mass transfer in a bubble column. Chem. Eng. J. 180, 216-228. http://dx.doi.org/10.1016/j.cej.2011.09.117.

Freitas, C. 2002. Bioreactores Multifásicos-Caracterização Hidrodinámica e de Transferência de Massa (in Portuguese). University of Minho, Portugal.

Freitas, C., Teixeira, J.A., 1998. Hydrodynamic studies in an airlift reactor with an enlarged degassing zone. Bioprocess Eng. 18, 267. http://dx.doi.org/10.1007/ s004490050441.

Hamad, F.A., He, S., 2010. Evaluation of hot-film, dual optical and Pitot tube probes for liquid-liquid two-phase flow measurements. Flow Meas. Instrum. 21, 302-311. http://dx.doi.org/10.1016/j.flowmeasinst 2010.03.004.

Hooshyar, N., Hamersma, P.J., Mudde, R.F., van Ommen, J.R., 2010. Gas Fraction and Bubble Dynamics in Structured Slurry Bubble Columns. Industrial \& Engineering Chemistry Research 49, 10689-10697.

Hong, M., Cartellier, A., Hopfinger, E.J., 2004. Characterization of phase detection optical probes for the measurement of the dispersed phase parameters in sprays. Int. J. Multiph. Flow 30, 615-648. http://dx.doi.org/10.1016/j. ijmultiphaseflow.2004.04.004.

Jamialahmadi, M., Muller-Steinhagen, H., 1991. Effect of solid particles on gas holdup in bubble columns. Can. J. Chem. Eng. 69, 390-393.

Jhawar, A.K., Prakash, A., 2007. Analysis of local heat transfer and hydrodynamics in a bubble column using fast response probes. Chem. Eng. Sci. 62, 7274-7281. http://dx.doi.org/10.1016/j.ces.2007.08.026.

Klein, J., Vicente, A.A., Teixeira, J.A., 2003. Hydrodynamic considerations on optimal design of a three-phase airlift bioreactor with high solids loading. J. Chem Technol. Biotechnol. 78, 935-944. http://dx.doi.org/10.1002/jctb.889.

Lehnert, R., Kurec, M., Brányik, T., Teixeira, J.A., 2008. Effect of oxygen supply on flavor formation during continuous alcohol-free beer production: a model study. J. Am. Soc. Brew. Chem. 66, 233-238.

Lu, W., Hwang, S., Chang, C., 1995. Liquid velocity and gas holdup in three-phase internal loop airlift reactors with low-density particles. Chemical Engineering Science 50, 1301-1310.

Luo, H.P., Al-Dahhan, M.H., 2010. Local gas holdup in a draft tube airlift bioreactor. Chem. Eng. Sci. 65, 4503-4510. http://dx.doi.org/10.1016/j.ces.2010.04.037.

Mena, P.C., Pons, M.N., Teixeira, J.A., Rocha, F.A., 2005a. Effect of solids on gas-liquid mass transfer and bubble characteristics in three-phase systems.

Mena, P.C., Rocha, F.A., Teixeira, J.A., Sechet, P., Cartellier, A., 2008. Measurement of gas phase characteristics using a monofibre optical probe in a three-phase flow. Chem. Eng. Sci. 63, 4100-4115. http://dx.doi.org/10.1016/j.ces.2008.05.010.

Mena, P.C., Ružička, M.C., Rocha, F.A., Teixeira, J.A., Drahoš, J., 2005b. Effect of solids on homogeneous-heterogeneous flow regime transition in bubble columns. Chem. Eng. Sci. 60, 6013-6026. http://dx.doi.org/10.1016/j.ces.2005.04.020.

Mota, A., Novak, P., Macieira, F., Vicente, A.A., Teixeira, J.A., Smogrovicova, D., Brányik, T., 2011. Formation of flavor-active compounds during continuous alcohol-free beer production: the influence of yeast strain, reactor configuration, and carrier type. J. Am. Soc. Brew. Chem. 69, 1-7.

Mussatto, S.I., Aguilar, C.N., Rodrigues, L.R., Teixeira, J. a, 2009. Colonization of Aspergillus japonicus on synthetic materials and application to the production of fructooligosaccharides. Carbohydr. Res. 344, 795-800. http://dx.doi.org/ 10.1016/j.carres.2009.01.025.

Olivieri, G., Marzocchella, A., van Ommen, J.R., Salatino, P., 2007. Local and global hydrodynamics in a two-phase internal loop airlift. Chem. Eng. Sci. 62, 7068-7077. http://dx.doi.org/10.1016/j.ces.2007.08.029. 
Shen, X., Mishima, K., Nakamura, H., 2008. Error reduction, evaluation and correction for the intrusive optical four-sensor probe measurement in multidimensional two-phase flow. Int. J. Heat Mass Transf. 51, 882-895. http://dx. doi.org/10.1016/j.ijheatmasstransfer.2006.01.054.

Tomiyama, A., Celata, G.P., Hosokawa, S., Yoshida, S., 2002. Terminal velocity of single bubbles in surface tension force dominant regime. Int. J. Multiph. Flow 28, 1497-1519. http://dx.doi.org/10.1016/S0301-9322(02)00032-0.

Unadkat, H., Rielly, C.D., Hargrave, G.K., Nagy, Z.K., 2009. Application of fluorescent PIV and digital image analysis to measure turbulence properties of solid-liquid stirred suspensions. Chem. Eng. Res. Des. 87, 573-586. http://dx.doi.org/ 10.1016/j.cherd.2008.11.011.
Van der Zon, M., Hamersma, P.J., Poels, E.K., Bliek, A., 2002. Coalescence of freely moving bubbles in water by the action of suspended hydrophobic particles. Chem. Eng. Sci. 57, 4845-4853. http://dx.doi.org/10.1016/S0009-2509(02) 00281-6.

Vejražka, J., Večeř, M., Orvalho, S., Sechet, P., Ružička, M.C., Cartellier, A., 2010. Measurement accuracy of a mono-fiber optical probe in a bubbly flow. Int. J. Multiph. Flow 36, 533-548. http://dx.doi.org/10.1016/j.ijmultiphaseflow. 2010.03.007.

Wu, C., Suddard, K., Al-dahhan, M.H., 2008, Bubble dynamics investigation in a slurry bubble column. AIChE Journal 54, 1203-1212. 